\title{
Bolsonarismo e o homo delinquens
}

\author{
Bolsonarism y el homo delinquens \\ Bolsonarism and the homo delinquens
}

\author{
Ana Tázia Patricio DE MELO CARDOSO \\ Universidade Federal do Rio Grande do Norte - UFRN (Brasil) \\ anataziaprof@gmail.com
}

\author{
Alexsandro Galeno ARAÚJO DANTAS \\ Universidade Federal do Rio Grande do Norte - UFRN (Brasil) \\ alexgalenno@gmail.com

\section{Patricia Rilliane GOMES DA SILVA} \\ Universidade Federal do Rio Grande do Norte - UFRN (Brasil) \\ patriciarilrn@hotmail.com
}

Chasqui. Revista Latinoamericana de Comunicación

N. ${ }^{\circ}$ 148, diciembre 2021 - marzo 2022 (Sección Monográfico, pp. 47-66)

ISSN 1390-1079 / e-ISSN 1390-924X

Ecuador: CIESPAL

Recibido: 20-05-2021 / Aprobado:05-11-2021 


\title{
Resumo
}

O bolsonarismo, sem ressalvas, constitui-se e se delineia como opinião a partir de linchamentos digitais, injúrias e falta de respeito. Motivado pela influência desse fenômeno no cenário político e comunicacional brasileiro, este artigo apresenta uma reflexão ensaística acerca desse tema, fomentada pela entrada em um grupo público de WhatsApp intitulado Direita do Rio Grande do Norte, formado por apoiadores do então presidente do Brasil, Jair Messias Bolsonaro (sem partido). Em campo, o silêncio foi nossa ferramenta principal, pois, qualquer comentário pode acender o alerta que sensibiliza os tênues limites da opinião bolsonarista. Dessa forma, salientamos o contágio sem contato que caracteriza a sociedade atual, na qual se expressa o homo delinquens.

Palavras-chave: fake news, WhatsApp, opinião, linchamentos virtuais.

\section{Resumen}

El bolsonarismo, sin reservas, se constituye y se perfila como una opinión basada en linchamientos digitales, lesiones y falta de respeto. Motivado por la influencia de este fenómeno en el escenario político y comunicacional brasileño, este artículo presenta una reflexión ensayística sobre este tema, impulsado por la entrada en un grupo público de WhatsApp titulado Direita do Rio Grande do Norte, formado por simpatizantes del entonces presidente de Brasil, Jair Messias Bolsonaro (sin partido). En el campo, el silencio fue nuestra principal herramienta, porque cualquier comentario puede encender la alerta que sensibiliza los tenues límites de la opinión bolsonarista. Así, destacamos el contagio sin contacto que caracteriza a la sociedad actual, en la que se expresa el homo delinquens.

Palabras clave: fake News, WhatsApp, opinión, linchamientos digitales.

\begin{abstract}
Bolsonarism, no exception, is constituted and is outlined as an opinion based on digital lynching, injuries and lack of respect. Motivated by the influence of this phenomenon in the Brazilian political and communicational scenario, this article presents an essay on this theme, stimulated by the entry into a public WhatsApp group entitled Direita do Rio Grande do Norte, formed by supporters of the then president of Brazil, Jair Messias Bolsonaro (without party). In the field, silence was our main tool, because any comment can ignite the alert that sensitizes the tenuous limits of Bolsonarist opinion. Thus, we highlight the contactless contagion that characterizes today's society, in which homo delinquens is expressed.
\end{abstract}

Keywords: fake news, WhatsApp, opinion, digital lynching. 


\section{Introdução}

O presidente Jair Messias Bolsonaro (sem partido) é a expressão, no Brasil, do que tem sido denominado de pós-verdade, devido à sua habilidade de produzir narrativas capazes de criar uma "realidade" mimetizada e sustentada pelo que Gabriel Tarde (2005) chamaria de uma multidão abstrata e soberana: a opinião. É imprescindível destacar a sutileza de um grupo social cuja ação, criminosa ou não, é tão mais real quanto menos aparente, uma vez que se converte em um público puramente psicológico, um estado de espírito concretizado pelas redes sociais digitais.

Vivemos uma certa normalização do modelo de exceção como modo de governo nas democracias contemporâneas em interface com as mídias digitais para o exercício pleno da biopolítica. ${ }^{1} \mathrm{O}$ filósofo Giorgio Agamben (2002) desenvolve a noção de estado de exceção relacionando à formação de regimes totalitários, apontando como os paradigmas das leis e das normas corroboram na formação de espaços não democráticos. Por essa ótica, podemos pensar a biopolítica como uma estratégia nefasta encarregada de fazer espalhar formas de vida desprovidas de potência.

Em sua obra Homo Sacer II, Agamben (2004) traz a definição de exceção como "o dispositivo original graças ao qual o direito refere-se à vida e a inclui em si por meio de sua própria suspensão" (Agamben, 2004, p. 12). O termo dispositivo (de inspiração foucaultiana) refere-se a instituições, medidas, discursos, proposições filosóficas e disposições voltados para governar a vida humana, com a suspensão do ordenamento jurídico e com a orientação estratégica de sujeição do sujeito em relação ao poder.

O autor afirma ainda que "soberano é aquele que decide sobre o estado de exceção" - que captura a vida por completo e é a "forma legal daquilo que não tem forma legal”- (Agamben, 2004, p. 12). Tal experiência é atualizada pelas relações digitais, e, no Brasil, podemos chamar de bolsonarismo: a falta de decoro, o desrespeito às leis e a normalização da mentira e/ou da relativização da verdade. Trata-se de um curso da história, no qual "a verdade é apenas mais uma participante do jogo, sem privilégios ou prerrogativas” (Dunker et al., 2017, p. 11).

Mas se a verdade é, de fato, secundarizada, quais são os valores que dão continuidade à ação bolsonarista? Uma mentira é capaz de sustentar um fluxo tão intenso de acontecimentos? Essa é uma problemática cara ao grupo de pesquisa Márginália, ${ }^{2}$ o qual é o provocador das reflexões que tecemos aqui

1 Michel Foucault versa, desde o poder pastoral, com as técnicas de governo das almas inventadas pela Igreja, até o neoliberalismo no século XX, sobre o conceito de governamentalidade para pensar as práticas governamentais e a racionalidade política do Ocidente. Assim, em suas obras Segurança, território, população (2008b [1977-1978]) e Nascimento da biopolítica (2008a[1978-1979]), esse autor nos ajuda a entender como somos concebidos em uma dimensão de governo que nos transforma em indivíduos governáveis.

2 O grupo de pesquisa Marginália é vinculado aos programas de pós-graduação em Comunicação e de 
a partir da análise do grupo de WhatsApp intitulado Direita do Rio Grande do Norte, uma vez que, enquanto pesquisadores, somos convocados a sustentar os fatos e, principalmente, a defender a legitimidade da narrativa científica, que parece ameaçada pela pós-verdade.

Sugestionados pelo exercício do contemporâneo, tal como Agamben (2009) o descreve, objetivamos produzir ou identificar os pontos de rompimento da história, a fim de enxergar as trevas do nosso tempo, neutralizando o brilho que irradia de tudo aquilo que é novo. Durante as eleições presidenciais de 2018, nos afogamos na corrente torrencial do mar digital, sem condições de explicar e digerir os acontecimentos e desnorteados no labirinto dos sentidos que influiu na eleição de um presidente despreparado, colérico e de ideias conservadoras.

Os participantes do grupo em análise são apoiadores do presidente Bolsonaro e, consequentemente, apoiadores ou repetidores, de seus posicionamentos. Não objetivamos reduzi-los a ingênuos ou ignorantes; pelo contrário, tencionamos ressaltar a fabricação do bolsonarismo a partir do contágio de desinformações, que adentram canais obscuros das microrrelações, cuja verdade é, necessariamente, fabricada. Parafraseando Angela Nagle (2017), isso reflete o que há de pior no universo da Internet, pois não se trata mais daquela extrema direita norte-americana que defendia ideias conservadoras. Mas, que usa a transgressão (arma da contracultura dos anos sessenta) mais atenta aos novos tempos e aproveitando tudo que a Internet permite. Foi assim na eleição de Donald Trump nos Estados Unidos, e também no Brasil, com a eleição de Bolsonaro.

\section{Metodologia}

A circulação de conteúdos falsos, notadamente, é operativa no WhatsApp. ${ }^{3}$ No Brasil, são mais de 130 milhões ${ }^{4}$ de usuários, com números crescentes, ${ }^{5}$ sendo uma das plataformas digitais mais populares e proeminente na abertura de mundos possíveis ${ }^{6}$ por oferecer uma conexão não intermediada entre os usuários, com ênfase ao acesso privado. Dessa forma, a conversação foi atualizada em seus aspectos fundamentais sublinhados por Tarde (2005): a imitação, a propagação de sentimento e de modos de ação.

Ciências Sociais da Universidade Federal do Rio Grande do Norte. Os pesquisadores que constituem o Grupo de pesquisa têm sua trajetória acadêmica marcada por incursões transdisciplinares, que envolveram sempre investigações que buscavam religar cultura, comunicação, arte e filosofia.

3 Pesquisa realizada pela Fundação Oswaldo Cruz aponta que 73,7\% das notícias falsas sobre o novo coronavírus circularam pelo WhatsApp (Nitahara, 2020).

4 Com cerca de 1,5 bilhões de usuários, o Aplicativo é a maior rede social de troca de mensagens do mundo (Valente, 2019).

5 No Brasil, 79\% da população usa internet fixa ou móvel (IBGE, 2019).

6 Para Gabriel Tarde (2003) neomonadologia está na impenetrabilidade das mônadas: elas são exteriores umas às outras, levando a admitir uma vigorosa interpenetração dessas forças heterogêneas que formam o mundo. Ele propõe a reformulação do conceito de mônadas, ou seja, não mais como universos fechados em si mesmos, mas, ao contrário, dando possibilidades de abrir portas e janelas para poder existir uma real comunicação entre elas, num solo de pura imanência. 
Embora seja um aplicativo de mensagens cujos grupos são limitados a 256 participantes, o seu impacto massivo corresponde a uma organização fluida coexistente com redes cotidianas tais como familiares, profissionais, religiosas e etc. Interessados nessa conversação e nas narrativas mobilizadoras, entramos no grupo público Direita do Rio Grande do Norte por meio de um link de acesso. Desde abril de 2020 (não definimos uma data para saída), acompanhamos os conteúdos e discussões que se estabelecem lá, a fim de analisar suas particularidades na fabricação simbólica do "mito". Cuidadosamente, a entrada no grupo foi silenciosa, pois, essa é a melhor maneira de mostrar concordância com tudo que era postulado, ou seja, Bolsonaro é honesto, sincero e sua luta é contra a corrupção.

Esta pesquisa visa contribuir com reflexões qualitativas sobre a circulação de ações e informações políticas de direita no digital, especialmente em razão do potencial do WhatsApp. De modo geral, as mensagens apresentam um tom de denúncia, assumindo um viés de indignação e busca de justiça para um país imerso na corrupção e na mentira. Lá, é notório que o mundo se divide em dois: o dos comunistas e da mentira, de um lado, e o dos patriotas com coragem para trazer a verdade, de outro (eles). Trata-se de uma batalha. Eles, "guerreiros da nação”, são lúcidos. Tomados pelo sentimento moral, estão lutando pelo justo e pelo amor ao país. Por isso, emocionam-se diante das palavras do presidente, referem-se a ele de maneira apaixonada.

Longe do dissenso, no grupo reina um espírito de harmonia, de "estar do lado certo”. Paz que acaba ao menor sinal de controvérsia, mas, heroicamente, eles estão prontos para defender e salvar os valores cristãos do cidadão de bem e da nação. $\mathrm{O}$ "excesso de verdade" do presidente explica o fato de ele estar sozinho e sendo atacado. Portanto, é preciso estar sempre alerta, porque é uma guerra, e eles estão do lado de "Deus e da verdade contra o comunismo". Nesse sentido, ter uma opinião se torna um imperativo de pertencimento ao grupo, e essa opinião pode ser sintetizada: "Bolsonaro tem razão".

\section{Discussão}

Freud (2010) afirma que quando os indivíduos se veem ameaçados pela fantasia do medo, negociam imaginariamente o ideal de liberdade futura por uma pretensa promessa de segurança no presente. $\mathrm{O}$ medo faz parte da economia subjetiva societal. Por isso, em geral, se transforma em moeda de troca. É assim que, nas grandes cidades, certamente, alimenta-se a indústria da segurança privada e a propagação de programas televisivos, que são arenas midiáticas do teatro das crueldades cotidianas. Roubos, assassinatos, estupros, sequestros servem de inspiração para o roteiro da fun morality. Dessa forma, a tragédia diária vira entretenimento, animada por apresentadores justiceiros prometeicos de uma pretensa sociedade sem crimes. 
A espetacularização da violência através de símbolos que incutem medo e criam a necessidade imaginária de justiceiros é propagada a fim de vender o discurso da ordem, e, também, o da punição como garantia aos indivíduos. É a partir desse fenômeno que apresentadores e militares têm se tornado políticos estrelas aos olhos da população. É nesse caldo de cultura política que emerge Bolsonaro: o animador de uma ópera bufa que brada, na verdade, valentia, ódio, desprezo pela vida, desrespeito e crueldade.

Gustav Le Bon (2019) dizia que só imagens trágicas nos comovem. E quanto mais chocantes, melhor para nosso gozo com o espetáculo. Por isso, cenas do naufrágio do Titanic ou de lutas de leões devorando gente em arenas romanas tornaram-se épicas. É sabido que, nas antigas arenas romanas, os reis se divertiam com lutas de gladiadores e com corpos de pessoas escravizadas jogados aos leões para serem devorados vivos. Tal prática era considerada diversão para nobres e para a população.

Uma vez que as arenas eram as medias da época, o espetáculo de matar e ser morto (uma tarefa de gladiadores e leões famintos por carne e sangue) e o belicismo bárbaro eram tidos como naturais. Inclusive, os enforcamentos em praça pública foram outra prática corrente na história. No faroeste americano, são comuns tais cenas: "mocinho" e "bandido" são, muitas vezes, julgados em praça pública, acompanhados pela fúria e excitação da população. Quando não são salvos pela arma de algum comparsa que "corta" a corda, são condenados ao cadafalso e à forca.

Mais um exemplo histórico da barbárie que inspira o bolsonarismo nos é dado por Michel Foucault (1987), que destaca o célebre caso de Damiens, ocorrido em 1757, que teve seu corpo desmembrado por cavalos amarrados em braços e pernas enquanto tudo isso era acompanhado pelo olhar de populares. São cenas de suplício como espetáculo, às quais ainda podemos perceber, à medida que a transmutação de tais práticas migrou para os meios de comunicação. Embora não tenha mais cadafalsos, espadas e leões famintos para devorar corpos de humanos, as medias atuais usam a mesma força publicitária e o comportamento de juízes, xerifes e terroristas: quanto mais massacre simbólico das vítimas, mais audiência. Nagle (2017) atualiza esse cenário no digital com maestria, ao descrever as guerras culturais na internet, que contaram com a ajuda de um exército memético vindo de todos os lados, obedecendo a qualquer convocação para os atos de perseguição, que levaram Trump a presidência.

Zygmunt Bauman (1998) afirma que existem, na história humana, três motivos para que tenhamos medo. O primeiro é a ignorância perante adversidades, infortúnios sociais e tragédias naturais, pois, muitas vezes, não se sabe ao certo suas origens e o que poderão se tornar no futuro. O segundo é a sensação de impotência diante de infortúnios ou catástrofes, isto é, o sentimento de que não há como evitar as suas consequências. Por último, o sociólogo destaca a humilhação como um dos motivos para o medo. Ela é apavorante porque atinge a autoestima e a autoconfiança humanas. 
Logo, o medo deriva da impotência em resolver os infortúnios, de modo que somos tragados por ela. Bauman (1998) relembra Freud (2010) e destaca três situações geradoras de angústias e medos: a continuada sensação de que a natureza é algo superior; a terrível sensação de que nossos corpos são frágeis; e, por último, o medo diante dos seres humanos. Os discursos que dão sustentabilidade a Bolsonaro não são, portanto, nada recentes (apesar da atualidade), pois proliferam a promessa de enfrentar as adversidades humanas a partir das imagens da valentia e do justiceiro.

As condições de insegurança das populações nas cidades perante o crime organizado, a ausência de assistência do Estado para prover os serviços básicos, como, por exemplo, saúde, educação, lazer, moradia e transporte, materializam os motivos e razões sociais e culturais destacadas por Freud (citado por Bauman, 1998). Diante do medo, as pessoas negociam suas liberdades futuras em troca de uma virtual segurança no presente. Desse modo, Bolsonaro é um mito criado para satisfazer a necessidade da população de se sentir protegida, prometendo segurança e felicidade a partir da construção, em rede, do herói matador, que permitirá acesso a armas de fogo para nosso bem.

Tal promessa oferece, notoriamente, meios práticos. Isso é evidenciado no comportamento de Bolsonaro em relação à pandemia, por exemplo: não usar máscara, relativizar o poder de validade da ciência e se expor em praça pública - como o mito prometeico da erradicação do vírus-, o que, sem dúvidas, tem lhe rendido forte apoio político e social. Esse respaldo se faz por uma eficiente narrativa midiática do presidente Bolsonaro nas redes sociais digitais e pela sustentação de canais de televisão aliados (Rede Record e SBT).

Ademais, tem a forte sustentação de instituições religiosas e militares. Como Freud (2011) ressalta sobre o medo, além de heróis míticos, são necessárias, ainda, instituições que sirvam de segurança aos sujeitos em sociedade. $\mathrm{O}$ autor destaca a Igreja e o Exército como "duas massas artificiais" (Freud, 2011).7 No grupo, essas instituições são referências fundamentais para os discursos propagados. Como veremos em alguns exemplos a seguir, elas sustentam a "seriedade" do compromisso moral de Bolsonaro com a nação conservadora, cristã e militarizada na versão digital.

\subsection{Dá trabalho ser bolsonarista}

Não raro, descrevemos o bolsonarismo como ingenuidade, má-fé ou ignorância, pois a diferença entre fatos e fetiches, respectivamente saber e ilusão (Latour,

7 A composição dos cargos do governo com militares e religiosos são de forte destaque na história do Brasil. Destacam-se: o Ministério da Mulher, da Família e dos Direitos Humanos, que tem a evangélica Damares Alves como titular; e o Ministério da Educação, que tem como titular o pastor Milton Ribeiro. No que tange aos militares, suas presenças em cargos do governo é sem precedentes. Segundo o portal GI (LIS, 2020, $n$. p.), "Levantamento do Tribunal de Contas da União (TCU) identificou 6.157 militares da ativa e da reserva em cargos civis no governo do presidente Jair Bolsonaro. O número é mais que o dobro do que havia em 2018, no governo Michel Temer (2.765)". Atualmente, são dez militares no governo com status de ministro. 
2002) é cara à nossa compreensão da realidade. Em razão disso, tratar Bolsonaro como um tipo de herói da nação é colocado na conta dos estados mentais ou das emoções. Porém, é conveniente observar o universo prático desse acontecimento, pois, sem perceber o intenso trabalho de fabricação e de criação do "mito", não podemos minimante pensar sobre esse fenômeno.

O espírito público cresce e se torna irresistível, tanto quanto for maior o número do público quanto mais grandiosa for a opinião, e, quanto mais regular e repetitiva for a satisfação dessa necessidade (Tarde, 2005). Em razão disso, a existência do bolsonarismo não é, simploriamente, resultante, puramente, da ingenuidade ou ignorância de seus adeptos. Pelo contrário, não se trata de acreditar que eles acreditam no que falam nem mesmo que agem absolutamente de má-fé. Comete-se, ainda, um equívoco ao querer superar a questão simplesmente respondendo aos boatos ou às inverdades disseminadas no e pelo grupo.

Se observarmos com menos perplexidade, notamos que algumas das fake news, conforme se convencionou chamar as mentiras propagadas, nem mesmo são dignas de serem colocadas em questão, tendo em vista que são tão absurdas quanto facilmente desmentidas. Como, por exemplo, o boato segundo o qual Fernando Haddad (candidato do Partido dos Trabalhadores que concorreu em 2018 com Bolsonaro) distribuiu mamadeira com formato de um pênis para crianças de creches em São Paulo, porque isso é de tão fácil superação que subestima o contágio que garantiu a faixa presidencial a Bolsonaro.

Tais questões nos levam a armadilhas do contágio, por isso nossos objetivos passam longe de discorrer por essas questões tão inúteis - tentar provar que isso é mentira não toca no cerne da questão; os bolsonaristas nem acreditam nisso nem pedem que acreditemos. A fabricação do bolsonarismo perpassa por outro modo de existir e de falar, por outras condições de verdade e, nesse sentido, não podemos dizer que o mito da direita não falou politicamente. Ele representou muito bem, encontrou solo fértil preparado pela mídia tradicional para cultivar o ódio ao Partido dos Trabalhadores e aos seus representantes.

A expressão \#BolsonaroTemRazao sintetiza uma ação em rede (Latour, 2002), que supera cada um dos agentes ou atores envolvidos. Isso significa dizer que o bolsonarismo, enquanto acontecimento, pode ganhar autonomia, porque aquele que age não tem domínio sobre o que fez, é necessariamente superado e passa à ação. Dessa forma, a construção do "mito" não depende da crença na mamadeira citada, da afirmação de que são enterrados caixões vazios para forjar números altos de mortos na pandemia, mas, sim, da atitude repetida, imitada, redita. É uma questão de ação.

Como ressalta Latour (2002), esses deslocadores de ação, essas forças que fabricamos, podem existir à medida que nos superam. Dizem a verdade porque atende a uma determinada condição de felicidade. O bolsonarismo é, portanto, ação, resulta do trabalho de uma multidão de agentes, de uma experimentação tecnopolítica, ou seja, da produção de acontecimentos focados 
nas sensibilidades, para, então, produzir outros acontecimentos, engendrando um ciclo contínuo que se retroalimenta, mas que, sobretudo, depende da continuação desse trabalho discursivo para continuar existindo.

\subsection{O "amor à pátria" e a "aliança com Deus"}

Corroborando com Tarde (2005), não há muitos motivos para se surpreender quando vemos aquele que se entrega tanto à opinião, sem mesmo perceber que seu caráter se debilitou. No grupo, é notável o trabalho ostensivo voltado para a construção do "mito" através do autoritarismo, do nacionalismo e do fundamentalismo religioso. Tais aspectos são as bases do dispositivo (Foucault, 2008a), uma gestão específica de governo que leva à subjetivação e à (des) subjetivação dos sujeitos. Agamben (2011) complementa a noção de dispositivo desenvolvida por Foucault afirmando que nesse se encontra o desejo de felicidade pelo indivíduo. Essa é uma busca permanente e a satisfação vem por meio de instrumentos de captura, cada vez mais avançados e sofisticados. O WhatsApp viabiliza tal satisfação e captura, explorando a circulação de imagens. Aliás, abusando dessa circulação mimetizada, conforme é exemplificada nas Figuras 1(a) e 1(b).

Figuras 1(a) e 1(b). Posts realçando a admiração e a admissão do próprio engajamento na luta política e ideológica de Bolsonaro

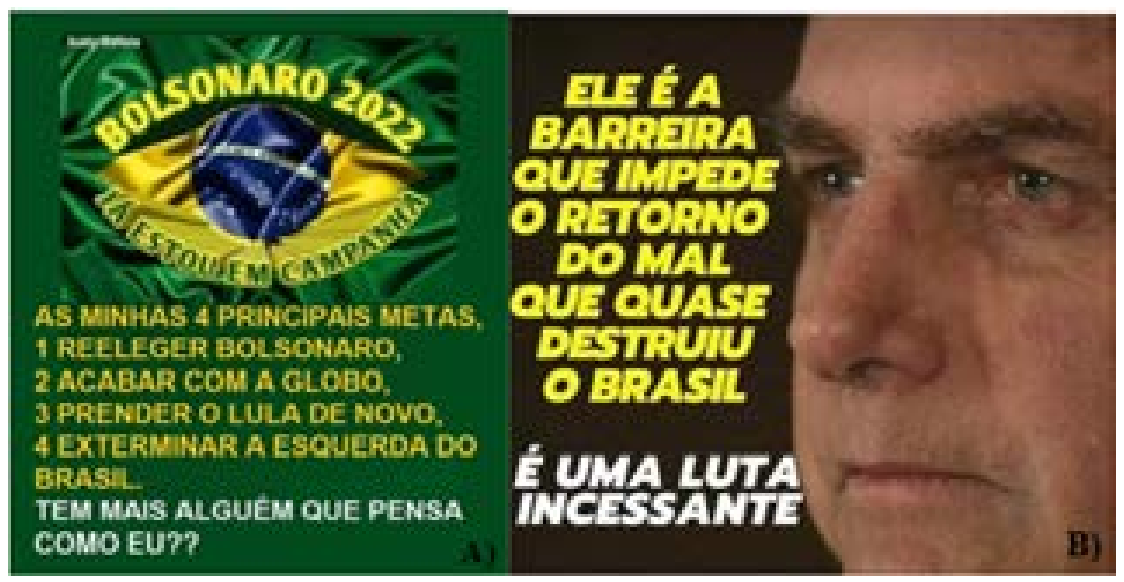

Fonte: Grupo de WhatsApp Direita do Rio Grande do Norte

O grupo refaz e rediz, obsessivamente, os objetivos resumidos na Figura 1(a), usando o "amor à pátria" e a "aliança com Deus" para justificar sua luta política, ilustrada por meio de um apelo sentimental, apaixonado e arrebatador na Figura 1(b). Logo, o emblema bolsonarista, presente na Figura 2, é um dos 
mais reproduzidos, já que o suporte digital disponível facilita o processo, com a utilização de propagação algorítmica das mensagens e com o uso de perfis robotizados pagos.

Figura 2. Post usando o emblema bolsonarista

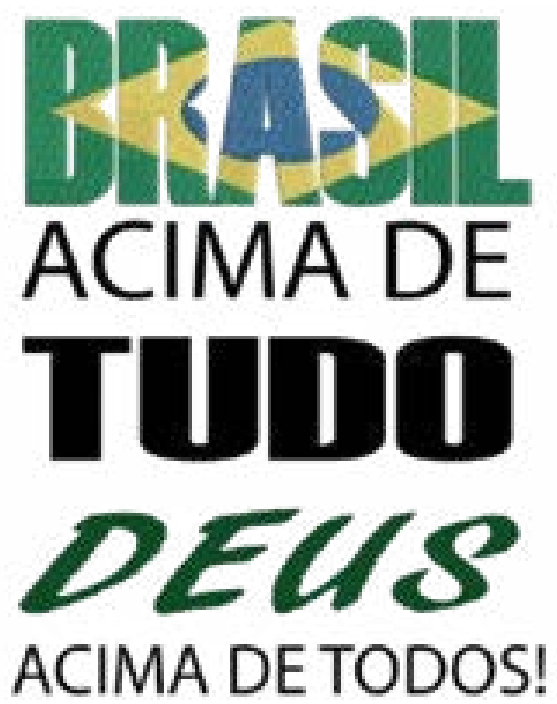

Fonte: Grupo de WhatsApp Direita do Rio Grande do Norte

"Brasil acima de tudo, Deus acima de todos" não pode ser descrito como um jargão autoritário, uma frase de efeito sem conexão com um estado de espírito passivo, forjado. A capacidade de inspirar algo que já coincida com um certo estado de espírito disseminado na população é, ainda, uma das chaves do contágio a ser considerada. Visto que, dando uma expressão comum àquilo que já estava pouco intenso e ainda não contagioso, cria-se uma força coletiva (Tarde, 2005).

No caso do bolsonarismo, tal expressão comum, uma vez que se adapta ao movimento peculiar das redes sociais digitais, estabelece suas condições de verdade a partir da linguagem dos memes: adaptam-se às circunstancias favoráveis à erosão da hierarquia, ao imediatismo do consumo e à ausência de respeito (Silva, 2019), como é exemplificado na Figura 3. 


\section{Figura 3. Sticker ou figurinha de WhatsApp usando a imagem de Bolsonaro} fazendo um passo de funk

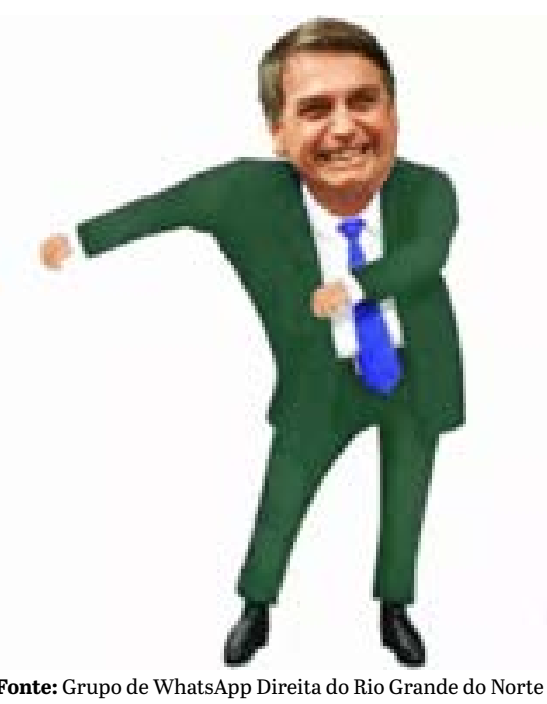

O sticker, na Figura 3, é usado para sugerir que vencemos uma guerra de opinião, que foi dado o melhor argumento ou, usando um termo das redes digitais, que "mitou". Seguindo a lógica da linguagem dos memes, os conteúdos do grupo podem apresentar um caráter ambíguo, ou seja, possuem uma forma de liberdade da moral institucional, pois não se sentem presos às normas e à seriedade (Silva, 2019). O esforço de mostrar que Bolsonaro não pode prescrever a hidroxicloroquina, por exemplo, porque ele não é pesquisador e nem está se apoiando em uma pesquisa científica parece ingênuo, pois é óbvio.

A questão importante, e que escapa à reflexão, é que ele não está falando de ciência. Essa não é a razão que se aplica ao discurso bolsonarista, porque a existência desse acontecimento político não depende dos critérios de verdade da ciência. Além disso, em conformidade com Tarde (2005), quando o espírito de público se desenvolve a partir de correntes de circulação mental, o sentimento de ponderação se desfaz cada vez mais. Assim, de forma intolerante e presunçosa, exalta-se ou deprecia-se pessoas sob a escolta do rótulo de opinião, entendendo que tudo deve se submeter a essa, inclusive à verdade objetiva, caso a contrarie.

No universo digital, isso implicou em uma linguagem menos comprometida com uma realidade dura, elas aceleram acontecimentos. E nisso reside a confusão de sentidos, muitas vezes, quando tentamos analisar o comportamento que constitui o fenômeno bolsonarista. Sob tal enfoque, o esforço do bolsonarismo é voltado para fazer a produção de acontecimentos e de narrativas, na medida em que transversaliza estéticas e discursos concentrados em efeitos políticos 
(Cardoso, 2018). Um dos exemplos estético e comunicacional é uma paródia do clipe da música Despacito $^{8}$ que nos deparamos no grupo.

Figura 4. Capturas de tela de alguns momentos do vídeo com a paródia de Despacito
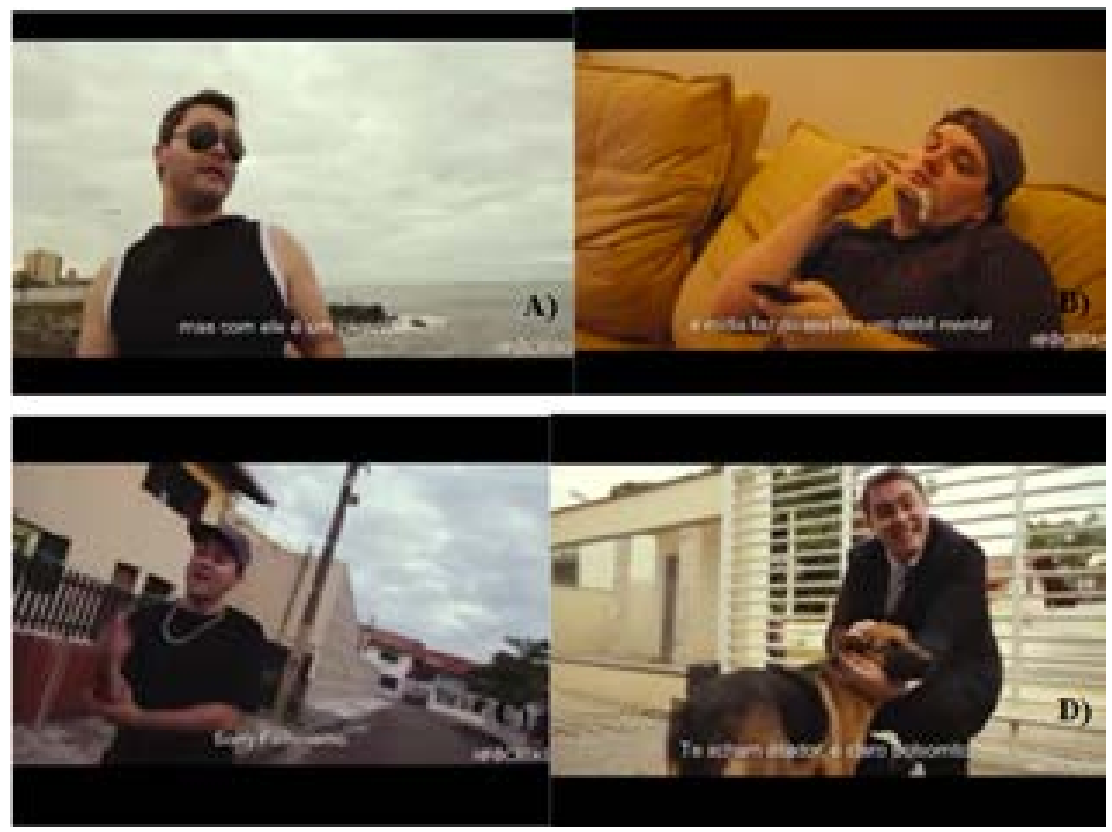

Fonte: Grupo de WhatsApp Direita do Rio Grande do Norte

Pelas sinuosidades de um fluxo infodêmico, essa paródia constitui um engajamento do tipo afetivo, que aproxima Bolsonaro dos seus seguidores através do sentimento de devoção e admiração. E isso é tão assustador quanto compreensível: trata-se de micromotivações afetivas estimuladas diariamente. Observemos algumas passagens da letra:

Enquanto roubam o tesouro nacional a mídia faz do teu filho um débil mental. Será que há algum que não seja corrupto?

BOL-SO-MI-TO

Devolver propina só o bolsomito. Para castrar os vagabundos que não guardam o pinto, meu voto minhas regras, sorry feminismo.

BOL-SO-MI-TO

8 O megahit latino Despacito, de Luis Fonsi e Daddy Yankee, alcançou o recorde de vídeo mais visto de todos os tempos do YouTube, em 2017. 
Te acham um ditador, é claro bolsomito. Pois em casa nunca foram corrigidos, se hoje alguém discorda, sentem-se oprimidos MITO SOBE, SOBE, SOBE

O intolerante mal que sai cuspido, por tolerantes bonzinhos, que matam bebês, salvam bandidos, SALVAM BANDIDOS, SALVAM BANDIDOS... Ofereça ao povo perversão e vitimismo, e mesmo comprovada a culpa, para sempre terás fãs convictos.

Os canhotos se desesperando, só um podre procurando, como não tão encontrando, vão mentiras vomitando. Quando era criança, faltou palmada no BUM-BUM-BUM

Hoje não distinguem quem é mal de quem é BOM-BOM

Vão para as ruas militar por causas que não sabem. Quero ver debater com Kataguiri [...]

QUE ISSO? QUE ISSO? É messias, mas não é cristo. Melhor se acostumar: é o mito é o mito... Diretas de pressa, Lula é o cabeça, tem que ser eleito antes da sentença [...].

A escolha do ritmo envolvente de Despacito, que, em 2017, chegou a ser a música mais ouvida do mundo, não é por acaso, pois, antes de capturar, é preciso atrair a atenção. E, então, sugerir uma ideia: a imprensa mente, as feministas mentem e a esquerda também mente. $O$ único verdadeiro e honesto é o presidente Bolsonaro, e, por isso, é atacado e caluniado. Dito isso, podemos ajustar a questão acerca do bolsonarismo: qual a importância de Bolsonaro ter razão? Por que ele tem razão?

$\mathrm{O}$ acontecimento Bolsonaro resulta numa ação que combina fatores míticos, políticos e comunicacionais. A dimensão imaginária e simbólica que envolve esse fenômeno se expressa pela identificação, quando os sujeitos projetam em um ex-deputado a ideia de capitão, símbolo do militarismo na política e de um defensor da moral cristã. Sendo, portanto, uma figura a ser seguida e defendida.

\subsection{Seguindo o presidente Bolsonaro}

O contágio bolsonarista, quando acionado, estabelece uma rede que transporta uma ideia que foi gestada nas microrrelações, especialmente as estabelecidas pelo WhatsApp. Usando os termos das redes digitais, viralizou, e, portanto, fez ser e acontecer a ideia de Bolsonaro presidente. Esse aplicativo foi capaz de simular o que Latour (2002) chama de passagem, da fabricação à realidade que nos supera enquanto indivíduos. É em razão disso que a postagem que ilustra a Figura 5 pode atestar. 
Figura 5. Post do grupo Direita do Rio Grande do Norte

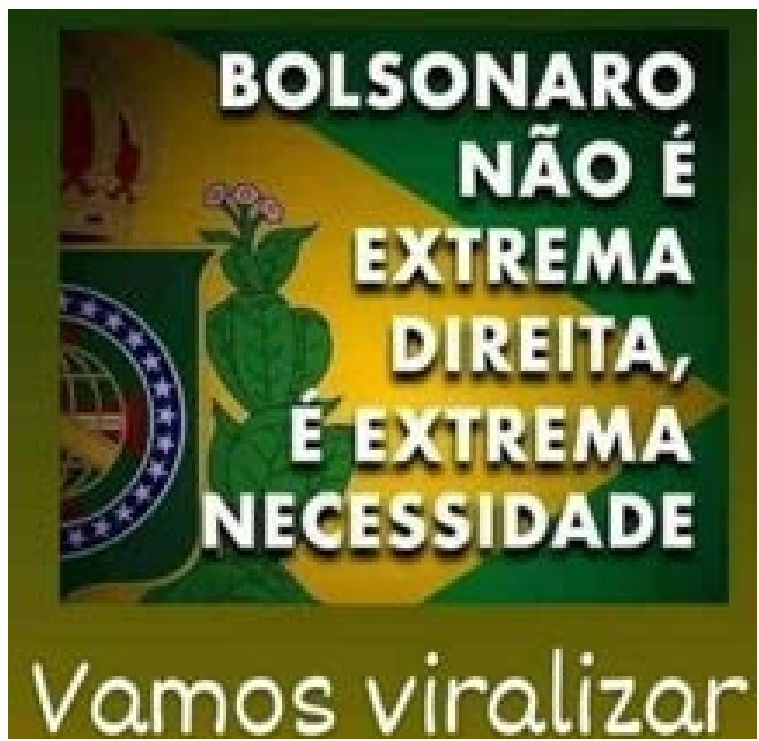

Fonte: Grupo de WhatsApp Direita do Rio Grande do Norte

No mundo atual, os dispositivos estabelecem uma crise constante e tendem a mais sujeição diante das diretrizes do poder. Usando os termos de Agamben (2010, p. 42):

Não seria provavelmente errado definir a fase extrema do desenvolvimento capitalista que estamos vivendo como uma gigantesca acumulação e proliferação dos dispositivos. Certamente, desde que apareceu o homo sapiens havia dispositivos, mas dir-se-ia que hoje não haveria um só instante na vida dos indivíduos que não seja modelado, contaminado ou controlado por algum dispositivo. De que modo, então podemos fazer frente a esta situação, qual a estratégia que devemos seguir no nosso quotidiano corpo a corpo com os dispositivos? Não se trata simplesmente de destruí-los, nem, como sugerem alguns ingênuos, de usá-los de modo correto. (Agamben, 2010, p. 42)

O WhatsApp está sendo usado de forma incorreta? Essa ferramenta oferece o meio mais eficiente para trocar mensagens (sejam de política ou não). Elas podem ecoar facilmente quando queremos alertar ou sentir a sensação de mostrar uma informação bombástica, conforme as Figuras 6(a) e 6(b) exemplificam: 
Figuras 6(a) e 6(b). Posts enfatizando o patriotismo e o apoio incondicional ao mito (como eles se referem a Bolsonaro)
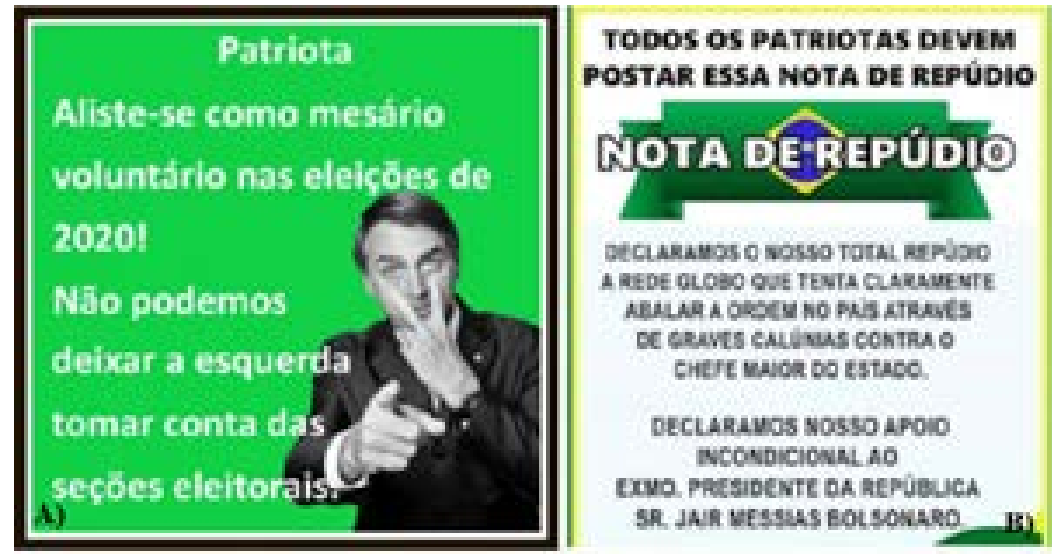

Fonte: Grupo de WhatsApp Direita do Rio Grande do Norte

Diferentemente de outras plataformas também populares, como Facebook e Instagram, o WhatsApp dá acesso principal aos perfis individualizados. Enquanto as duas primeiras oferecem, como acesso principal, as publicações abertas ao público, não conseguem estabelecer a aproximação necessária para alimentar as microrrelações, as influências mais íntimas e, como efeito, mais intensas. Dessa forma, o WhatsApp correspondeu a um importante meio de "faz-fazer" e "faz-falar" (Latour, 2002) do bolsonarismo. Nesse processo, no qual o indivíduo é superado, a rede tende a se ampliar.

$\mathrm{E}$, se focarmos em responder se a esquerda tem condições de manipular as urnas ou não, se a Globo ataca com calúnias o presidente Bolsonaro, como é pontuado nas postagens das Figuras 6(a) e 6(b), caímos em uma armadilha dos sentidos, pois são questões desinteressantes, que não serão ouvidas, porque são ultrajantes. Aliás, elas nem mesmo colocam em xeque a verdade que sustenta o bolsonarismo. Ousamos afirmar que nem mesmo os bolsonaristas acreditam nisso, menos ainda esperam que outros acreditem. Em suma, o contágio pelo WhatsApp acelera a sugestão vida de cima, de homens fisicamente separados, que outrora certamente estariam lendo o mesmo jornal, como descreve Tarde (2005) em razão da sua reflexão ter sido feita no início do século passado, mas, agora, estão, no mesmo grupo de um aplicativo de troca de mensagens.

\section{4. "espalhem", “compartilhem", "bomba"...}

Estão cada um em sua casa ou em outro lugar, fisicamente separados, mas conectados espiritualmente pelas crenças, cuja coesão consiste na convicção de que compartilham a mesma ideia. Nesse aspecto, o universo digital se sobressai. 
O grupo Direita do Rio Grande do Norte é significativamente alimentado por links que direcionam para blogs e redes sociais que se articulam para causarem a sensação de saber ou crer que fazem parte de um público muito maior. Nesse sentido, as mensagens vêm sempre acompanhadas de "espalhem", "compartilhem", "bomba" etc. Notoriamente, o grupo é um espaço capaz de criar esse sentimento, não com likes, deslikes ou quantidade de seguidores, como em outras redes sociais digitais, mas, especialmente, no sentido de repercutir, ecoar, reenviar, refletir, repetir, reproduzir, redizer, reiterar, à medida que se canaliza para outros grupos, ou mesmo no privado.

Basta colocar minimamente em questão a honestidade de Bolsonaro, para esses vínculos se desestabilizarem para iniciar os ataques. Com destaque para a Globo e para o ex-presidente Luís Inácio Lula da Silva, esses ataques podem ser resumidos com expressões "Globo lixo" e "Lulaladrão", usadas repetidas vezes para afirmar que a emissora usa a pandemia de covid-19 para destruir o presidente Bolsonaro e que Lula roubou o país. Além disso, a sensação de segurança de estar por trás de um teclado, como pontua Nagle (2017), escolta tais ataques que arruínam reputações, conforme esta pesquisa presenciou.

\section{Considerações finais}

Versamos sobre a complexa experiência do bolsonarismo a partir de um grupo de WhatsApp, e, inevitavelmente, constatamos cenas que podem deixar os sujeitos chocados com o fluxo de sensações, crenças, desejos manipulados para a fabricação de mundos. A pós-verdade pode ser descrita como esses acontecimentos, nos quais o conflito é gestado e faz parte do próprio processo de fabricação da realidade. As postagens no grupo Direita do Rio Grande do Norte estimulam a necessidade de reproduzi-las, sobretudo porque elas satisfazem a necessidade de pertencimento e de proteção de uma opinião que mantém a coesão do grupo.

Assim, todo o esforço de espalhamento do grupo é voltado para reforçar a percepção ou opinião que o delineia enquanto grupo. Tal opinião engaja um fluxo de ideias que visam legitimar suas ações políticas, que, mesmo desconexas da realidade objetiva, sustentam (pelo menos momentaneamente) a necessidade de existir que contagia os participantes do grupo. A condição de felicidade desse estado de coisas é dada na medida em que outros usuários se alinham a esse pensamento e o repetem ou o reproduzem, não apenas no grupo, mas, sobretudo, em outros espaços da vida social, somando-se a uma ação (o bolsonarismo) que cresceu (ou ainda cresce) essencialmente por meio de memes e debochando da oposição.

Os memes, as fake news, enfim, a circulação de conteúdo aparentemente sem nexo, com ofensas debochadas e ataques às oposições, foi apenas uma distração, uma armadilha que leva ao caminho aparentemente mais óbvio: apontar os erros absurdos que compõem o "mito". Porém, o que os bolsonaristas defendiam 
já era muito maior que eles, e a ação política aqui em questão resistiu a todas as tentativas, em certa medida até desesperadas, de desmentir suas ideias fracassou, foi tida como uma ultrajante violação a todos eles, que reagiram com mais fake news, mesmo que isso colocasse a vida deles, e até a vida de pessoas que eles amassem, em perigo.

Em razão disso, no grupo, foi preciso lidar com características comportamentais de sujeitos que se mobilizam politicamente pela proliferação do belicismo verbal. Os membros do grupo agem como o que Byung-Chul Han (2018) denomina de shitstorms, ou seja, reagem com violentos ataques a reputação das pessoas que sinalizem a menos discordância, mesmo interna. E isso precisa ser colocado em debate, como o verdadeiro desafio e questão dos intelectuais que estudam esse fenômeno.

Em consonância com Han (2018), no advento das redes sociais digitais vivenciamos uma era do encurtamento da distância e da diminuição do respeito. A palavra respeito (respectare) significa "olhar para trás". Significa um olhar com distância. Na sociedade atual, perdemos esse ethos civilizatório e a parcimônia da distância foi substituída pelo espetáculo (spectare), que significa voyeurismo de um olhar desprovido de alteridades. Usando os termos de Han (2018, p. 61): "uma sociedade sem respeito, sem o pathos da distância, desemboca numa sociedade do escândalo."

Se tudo vira espetáculo e escândalo, isso significa que o excesso de midiatização tem comprometido a necessidade fundamental de distinção entre o privado e o público. O excesso de exposição da intimidade, portanto, leva-nos a uma sociedade pornográfica. Inverte tudo aquilo que deveria ser da ordem do privado para o público. No território digital, a liberação da palavra, frequentemente, vem desprovida dessa distinção. Embora, como reflete Nagle (2017), a questão não seja apenas sobre a forma como a direita direcionou o debate, mas, também, como a esquerda se posicionou a tudo isso.

Por fim, ao assistirmos a uma intensa indiscrição de hábitos e injúrias que caracterizam o grupo de WhatsApp Direita do Rio Grande do Norte, assinalamos à ação do homo delinquens digital. Suas shitstorms aniquilam reputações e comprometem o respeito, que é sempre ligado ao nome; apontam suas armas para qualquer um que sugira, ou ao menos pareça sugerir, o mínimo de discordância. Não interessa o motivo nem as pessoas que serão atingidas. Quando se perde o respeito, elas abundam, configuram comportamentos de manadas e as pessoas têm seus nomes maculados pela violentamente. 


\section{Referências bibliográficas}

Agamben, G. (2004). Homo Sacer: Estado de exceção. II, I. Tradução de Iraci D. Poleti. São Paulo: Editora Boitempo.

Agamben, G. (2002). Homo Sacer: o poder soberano e a vida nua I. Tradução de Henrique Burigo. Belo Horizonte: Editora UFMG.

Agamben, G. (2009). O que é o contemporâneo? E outros ensaios. Tradução de Vinicius Nicastro Honesko. Chapecó: Argus.

Agamben, G. (2011). O reino e a glória: uma genealogia teológica da economia e do governo. Tradução de Selvino Assmann. São Paulo: Boitempo Editorial.

Bauman, Z. (1998). O mal-estar da pós-modernidade. Tradução de Mauro Gama e Claudia Martinelli Gama. Rio de Janeiro: Jorge Zahar.

Cardoso, A.T. (2018). O processo de impeachment de Dilma Rousseff. Micropolíticas do possível em Gabriel Tarde. (Tese Doutorado em Ciências Sociais) - Universidade Federal do Rio Grande do Norte, UFRN, Natal. Disponível em: https://sig https://repositorio. ufrn.br/jspui/handle/123456789/29663 aa.ufrn.br/sigaa/public/programa/defesas. jsf?lc $=$ pt_BR\&id $=360$

D’ancona, M. (2018). Pós-verdade: a nova guerra contra os fatos em tempos de fake news. Tradução de Carlos Szlak. Barueri: Faro Editorial.

Dunker, C. et al. (2017). Ética e pós-verdade. Porto Alegre: Dublinense.

Freud, S. (2010). O mal-estar na civilização. Novas conferências e outros textos (1930-1936). Tradução de Paulo César de Souza. São Paulo: Companhia das Letras.

Freud, S. (2011). Psicologia das massas e análise do eu e outros textos (1920-1923). Tradução de Paulo César de Souza. São Paulo: Companhia das Letras.

Foucault, M. (2008a). Nascimento da biopolítica. Tradução de Eduardo Brandão. São Paulo: Martins Fontes.

Foucault, M. (2008b). Segurança, território e população. Tradução de Eduardo Brandão. São Paulo: Martins Fontes.

Foucault, M. (1987). Vigiar e punir: história da violência nas prisões. Tradução de Raquel Ramalhete. Petrópolis: Vozes.

Han, B. (2018). O enxame. Perspectivas do digital. Tradução de Lucas Machado. São Paulo: Editora Vozes.

IBGE Educa. Uso de internet, televisão e celular no Brasil (2019). Disponível em: https:// educa.ibge.gov.br/jovens/materias-especiais/20787-uso-de-internet-televisao-e-celular-no-brasil.html

Latour, B. (2002). Reflexão sobre o culto moderno dos deuses fe(i)tiches. Tradução de Sandra Moreira. Bauru, SP: EDUSC.

Le Bon, G. (2019). Psicologia das multidões. Tradução de Mariana Sérvulo da Cunha. São Paulo: Martins Fontes.

Lis, L. (2020). Governo Bolsonaro mais que dobra número de militares em cargos civis, aponta TCU. Brasília: G1. Política. Disponível em: https://g1.globo.com/politica/noticia/2020/o7/17/governo-bolsonaro-tem-6157-militares-em-cargos-civis-diz-tcu.ghtml

Nagle, A. (2017). Kill All Normies: Online Culture Wars de 4chan e Tumblr a Trump and the Alt-Right. Winchester: Zero Books.

Nitahara, A. (2020). WhatsApp é principal rede de disseminação de fake news sobre covid-19. Agência Brasil. Disponível em: https://agenciabrasil.ebc.com.br/geral/noticia/2020-04/ whatsapp-e-principal-rede-de-disseminacao-de-fake-news-sobre-covid-19 
Posetti, J., e Ireton, C. (2019). Jornalismo, fake news \& desinformação: manual para educação e treinamento em jornalismo. Tradução de Sarah Rebouças Reedman. UNESCO. Disponível em: https://unesdoc.unesco.org/ark:/48223/pfoooo368647.

Silva, P. (2019). A insolência de um pensamento complexo: os memes do impeachment de Dilma Rousseff. (Dissertação Mestrado em Ciências Sociais) - Universidade Federal do Rio Grande do Norte, UFRN, Natal. Disponível em: https://repositorio.ufrn.br/handle/123456789/280oo.

Tarde, G. (2000). As leis da imitação. Tradução de Carlos Fernandes Maia e Maria Manuela Maia. Porto: Rés.

Tarde, G. (2005). A opinião e as massas. 2. ed. Tradução de Eduardo Brandão. São Paulo: Martins Fontes.

Tarde, G. (2003). Monadologia e sociologia. Tradução de Tiago Themudo. Petrópolis: Vozes.

Valente, J. (2019). Usuários de smartphone devem atualizar WhatsApp, orienta empresa. Brasília: Geral. Disponível em: https://agenciabrasil.ebc.com.br/geral/noticia/2019-05/ usuarios-de-smartphone-devem-atualizar-whatsapp-orienta-empresa 
